\title{
STRATEGI PENGEMBANGAN PEMASARAN INDUSTRI RUMAH TANGGA RAFLESIA DI DESA SUMBER AGUNG KECAMATAN ARMA JAYA KABUPATEN BENGKULU UTARA
}

\author{
Marketing Development Strategy of Home Industry Raflesia at Sumber \\ Agung Village, Arma Jaya Sub-District, Bengkulu Utara Regency \\ Dwi Lestari, Ketut Sukiyono dan Redy Badrudin \\ Jurusan Sosial Ekonomi Pertanian, Fakultas Pertanian Universitas Bengkulu
}

\begin{abstract}
The purpose of this research are (1) to determine the priority of the product should be developed and used as priority by Raflesia's home industry and (2) to determine the priority of marketing strategy appropriate and effective in the development of marketing home industry Raflesia for main products. The alternative have been used in selected the main products home industry Raflesia are Nila Crispy, Instan Jahe and Terong Crispy. Meanwhile the alternative have been used in selected development marketing strategy for the main products home industry Raflesia are 4P (product, price, distribution and promotion). To find the priority main products and marketing development strategy for the main product home industry Raflesia used Analytical Hierarchy Process (AHP) method. Based on the research, showed that the priority alternative products in a selected the main products home industry Raflesia are Instan Jahe, Nila Crispy and Terong Crispy with the weight $0.43,0.35,0.22$ respectively. Furthermore, the priority alternative strategy in the selected of marketing development strategy for instant Jahe product of home industry Raflesia are strategy of promotion, product, distribution and price with the weight $0.32,0.28,0.23,0.17$ respectively.
\end{abstract}

Keywords: Main products, marketing development strategic, AHP

\section{PENDAHULUAN}

Industri rumah tangga merupakan salah satu agroindustri berskala mikro, kecil dan menengah yang sedang berkembang pesat sekarang ini. Perkembangan sektor industri kecil dan menengah di Provinsi Bengkulu pada tahun 2011-2013 mengalami peningkatan baik dari unit usaha, tenaga kerja maupun nilai produksi. Dari tahun 2011-2013 satuan unit industri kecil dan menengah berturut-turut adalah 2001 unit, 3073 unit dan 3284 unit. Jumlah tenaga kerja dari tahun 2011-2013 berturut-turut adalah 8653 orang, 11160 orang dan 11519 orang. Sedangkan nilai produksi industri kecil dan menengah dari tahun 2011-2013 berturut-turut adalah Rp 203.590.342, Rp 384.682.224 dan Rp 
428.260.670 (BPS, 2014). Keadaan ini akan menyebabkan persaingan yang tajam karena banyaknya pesaing pelaku industri. Melihat hal tersebut, industri rumah tangga dituntut untuk lebih memperhatikan lingkungan yang dapat mempengaruhi industri, agar industri rumah tangga dapat mengetahui strategi pemasaran seperti apa dan bagaimana yang efektif yang harus diterapkan. Industri rumah tangga harus mengevaluasi strategi pemasarannya untuk menciptakan strategi pemasaran yang tepat agar industri dapat berkembang dan bertahan di pasaran.

Salah satu Industri Rumah Tangga yang ada di Provinsi Bengkulu yang berpotensi untuk dikembangkan adalah Industri Rumah Tangga RAFLESIA yang beralamatkan di Jln. Tri Dharma No. 06 RT 01 Desa Sumber Agung, Kecamatan Arma Jaya, Kabupaten Bengkulu Utara. Industri Rumah Tangga Raflesia memproduksi aneka makanan ringan dan minuman herbal seperti aneka ikan crispy dan makanan lainnya. Jenis-jenis produk yang diproduksi oleh industri rumah tangga Raflesia adalah terong crispy, beledang crispy, nila crispy, baby fish crispy, instan jahe, rengginang (rengginang ikan, bawang dan ketan), abon ikan tuna, teh makota dewa, teh sirih merah, stik durian, stik durian cokelat, stik jagung manis, sik wortel, stik sawi, stik abon tuna, keripik singkong, pisang sale dan minyak obat luka dari biji mahkota dewa. Dari berbagai macam produk tersebut, maka diperoleh 3 produk yang akan dianalisis untuk menentukan prioritas produk unggulan berdasarkan kriteria Disperindag tahun 2008 yakni terong crispy, nila crispy dan jahe instan.

Melihat banyaknya produk yang dihasilkan oleh industri rumah tangga Raflesia, ini menjadi daya tarik tersendiri bagi peneliti untuk lebih mengembangkan strategi pemasaran industri rumah tangga Raflesia. Produk yang dihasilkan terus bervariasi dan beragam sesuai dengan karakteristik dari komoditas pertanian yakni bersifat musiman. Sehingga produk yang dihasilkan kadang tidak menentu dan terus berinovasi sesuai dengan musim. Karena hal inilah, sehingga perlu ditentukan prioritas produk apa yang seharusnya diunggulkan oleh industri rumah tangga Raflesia. Kemudian, setelah mendapat rekomendasi produk unggulan industri rumah tangga Raflesia akan memudahkan dalam menentukan rumusan prioritas strategi pengembangan pemasaran produk unggulannya yang tepat. Salah satu kunci keberhasilan dalam menghadapi persaingan yakni adanya kemampuan dalam proses pengambilan keputusan secara tepat sasaran, cepat dan dapat dipertanggungjawabkan. Maka dalam penelitian ini, metode pengambilan keputusan untuk menentukan prioritas dari beberapa faktor atau alternatif strategi digunakan metode Analytical Hierarchy Process (AHP).

Berdasarkan latar belakang di atas, maka penelitian ini bertujuan (1) menentukan prioritas produk yang sebaiknya dikembangkan dan dijadikan unggulan oleh industri rumah tangga Raflesia dan (2) menentukan prioritas 
strategi pemasaran yang sesuai dan efektif dalam pengembangan pemasaran industri rumah tangga Raflesia untuk produk unggulannya.

\section{METODOLOGI PENELITIAN}

Penelitian ini dilakukan di Industri Rumah Tangga Raflesia di Desa Sumber Agung Kecamatan Arma Jaya Kabupaten Bengkulu Utara. Responden AHP yang dipilih merupakan ahli (expert) di bidangnya yakni pelaku usaha yakni pemilik/manajer industri rumah tangga Raflesia, akademisi yang memiliki pendidikan yang menunjang mengenai pemasaran di bidang UKM, Dinas Perindustrian, Perdagangan dan Koperasi (Disperindagkop) Kabupaten Bengkulu Utara selaku yang berwenang merumuskan kebijakan mengenai pemberdayaan UKM. Dalam penelitian ini, metode analisis data menggunakan software Expert Choice 11.

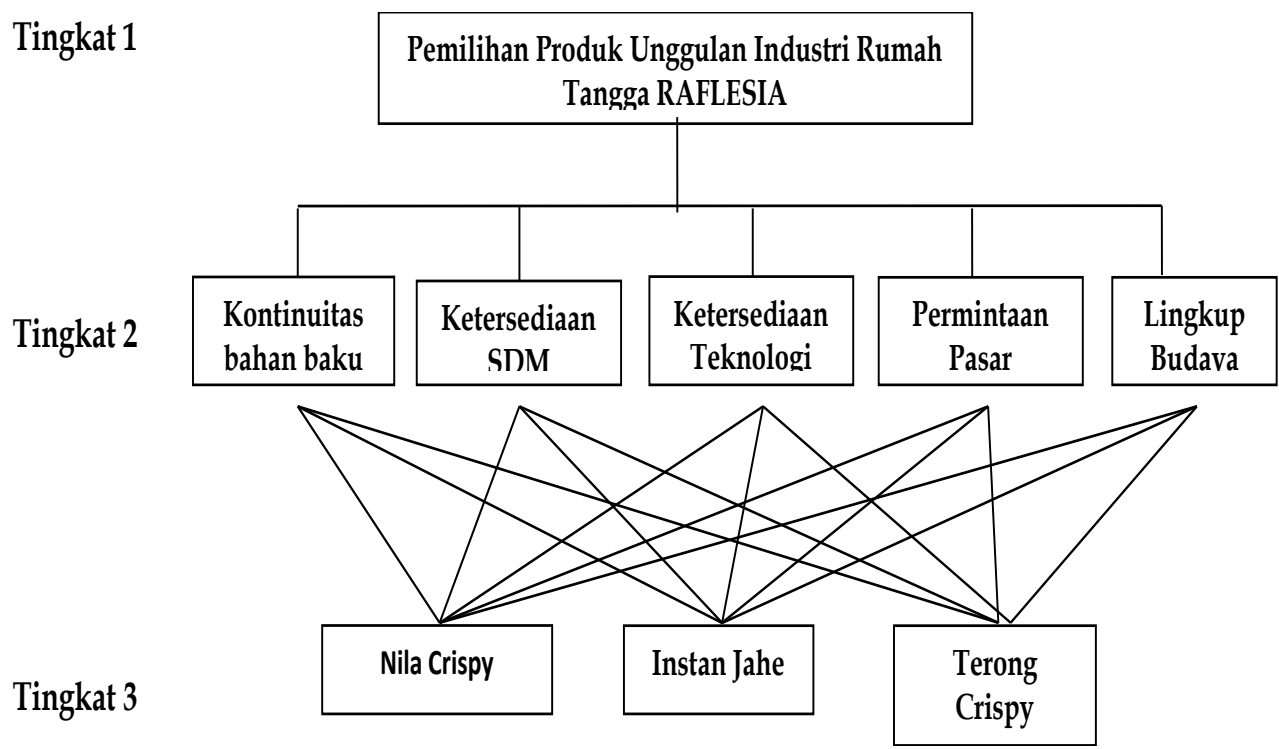

Gambar 1.

Struktur Hirarki Penentuan Produk Unggulan

Industri Rumah Tangga RAFLESIA 
Tingkat 1

Pemilihan Strategi Pengembangan Pemasaran untuk produk unggulan IRT RAFLESIA

Tingkat 2

Tingkat 3

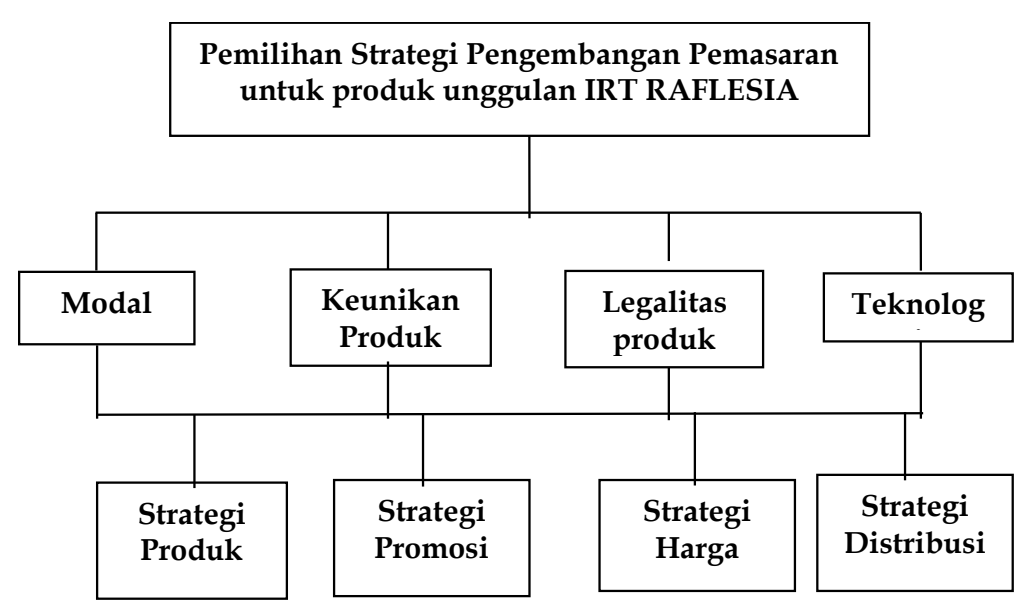

Gambar 2.

Struktur Hirarki Strategi Pengembangan Pemasaran Produk Unggulan IRT RAFLESIA

\section{HASIL DAN PEMBAHASAN}

\section{Karakteristik Responden}

Kriteria responden AHP dalam penelitian ini apabila responden memenuhi salah satu kriteria di bawah ini yaitu :

1. Memiliki kemampuan dan wewenang dalam merumuskan kebijakan industri rumah tangga Raflesia termasuk merumuskan strategi pemasaran industri rumah tangga Raflesia.

2. Memiliki pengetahuan yang menunjang di bidangnya.

3. Memiliki wewenang dalam merumuskan kebijakan terhadap pemberdayaan Usaha Kecil Menengah (UKM) baik sebagai fasilitator, mediator dan inovator.

Karakteristik yang dijadikan responden baik responden untuk pemilihan produk unggulan maupun pemilihan strategi pengembangan pemasaran produk unggulan industri rumah tangga Raflesia merupakan narasumber yang berasal dari pemilik industri Raflesia sebanyak 1 orang, Dinas Perindustrian dan Perdagangan Kab. Bengkulu Utara sebanyak 2 orang, Dinas Koperasi dan UKM Kab. Bengkulu Utara sebanyak 1 orang dan akademisi yang terdiri dari dosen Fakultas Pertanian sebanyak 2 orang.

150 | Dwi Lestari, Ketut Sukiyono, dan Redy Badrudin, Strategi Pengembangan. 


\section{Analisis Pemilihan Produk Unggulan Industri Rumah Tangga Raflesia}

Analisa penentuan produk unggulan pada industri rumah tangga Raflesia dengan menggunakan pendekatan AHP diawali dengan penentuan bobot pada masing - masing kriteria yang telah ditentukan sebelumnya. Hasil analisa bobot masing masing kriteria disajikan pada Tabel 1.

Tabel 1. Nilai Bobot Kriteria Pemilihan Produk Unggulan

\begin{tabular}{lcc}
\hline \multicolumn{1}{c}{ Kriteria } & Bobot & Prioritas \\
\hline Kontinuitas Bahan Baku & 0,28 & 2 \\
Ketersediaan SDM & 0,14 & 4 \\
Ketersediaan Teknologi & 0,17 & 3 \\
Permintaan Pasar & 0,30 & 1 \\
Lingkup Budaya & 0,11 & 5 \\
\hline Rasio Inkonsistensi Keseluruhan (\%) & & $\mathbf{0 , 9}$
\end{tabular}

Sumber : Data primer diolah (2015)

Dari 5 kriteria pada Tabel 1 di atas, permintaan pasar memperoleh prioritas pertama dengan bobot sebesar 0,30 dengan rasio inkonsistensi di bawah $10 \%$ sesuai persyaratan. Dalam menentukan produk unggulan industri rumah tangga Raflesia, aspek permintaan pasar merupakan salah satu aspek penting. Karena dasar dari penyediaan produk adalah banyaknya permintaan terhadap produk tersebut. Hal ini sesuai dengan penelitian yang dilakukan Soetarto dkk (2011) bahwa dalam mengidentifikasi produk unggulan Industri Kecil Menengah (IKM) seharusnya mempertimbangkan kondisi daerah dengan tetap memperhatikan kriteria persaingan seperti adanya nilai tambah yang tinggi, adanya sifat unik dan adanya keterkaitan dan peluang untuk bersaing di pasar luar daerah serta internasional. Sedangkan kriteria yang memperoleh prioritas terakhir merupakan kriteria lingkup budaya dengan besar bobot 0,1. Dalam menentukan produk unggulan, mengetahui dan memahami ciri khas dari kebudayaan di daerah yang akan dituju perlu dilakukan dikarenakan untuk melakukan terobosan pemasaran produk unggulan, pelaku usaha sebaiknya berfokus pada nilai-nilai yang dominan dalam suatu masyarakat.

Analisa selanjutnya adalah menentukan prioritas masing - masing komoditi yang didasarkan pada masing masing kriteria yang telah ditemukan. Hasil analisa ini ditunjukkan pada Tabel 2. Hasil pengolahan secara keseluruhan pada kriteria kontinuitas bahan baku di atas, telah memenuhi persyaratan dengan rasio inkonsistensi dibawah 10\%. Berdasarkan tabel 2 bahwa didapat produk Nila Crispy yang menjadi prioritas utama alternatif produk unggulan industri rumah tangga Raflesia berdasarkan kriteria kontinuitas bahan baku yakni produk Nila Crispy dengan bobot sebesar 0,41. Sebagai industri rumah tangga yang terletak di Kabupaten Bengkulu Utara, industri rumah tangga Raflesia dapat memperoleh bahan baku dari ketiga produk tersebut dari lokal. 
Hal ini dikarenakan oleh wilayah Bengkulu Utara merupakan wilayah pertanian yang didukung oleh data lapangan usaha utama di Kabupaten Bengkulu Utara yang menyebutkan bahwa lebih dari 50\% penduduknya bekerja di sektor pertanian (BPS, 2013).

\section{Tabel 2. Nilai Bobot Alternatif}

\begin{tabular}{|c|c|c|c|c|}
\hline $\begin{array}{c}\text { Kriteria } \\
\text { Produk } \\
\text { Unggulan } \\
\end{array}$ & $\begin{array}{l}\text { Alternatif } \\
\text { Produk }\end{array}$ & Bobot & Prioritas & $\begin{array}{c}\text { Rasio } \\
\text { Inkonsistensi } \\
(\%)\end{array}$ \\
\hline \multirow{3}{*}{$\begin{array}{l}\text { Kontinuitas } \\
\text { Bahan Baku }\end{array}$} & Nila Crispy & 0,41 & 1 & \multirow{3}{*}{0} \\
\hline & Instan Jahe & 0,40 & 2 & \\
\hline & Terong Crispy & 0,19 & 3 & \\
\hline \multirow{3}{*}{$\begin{array}{l}\text { Ketersediaan } \\
\text { SDM }\end{array}$} & Nila Crispy & 0,28 & 2 & \multirow{3}{*}{0} \\
\hline & Instan Jahe & 0,44 & 1 & \\
\hline & Terong Crispy & 0,28 & 2 & \\
\hline \multirow{3}{*}{$\begin{array}{l}\text { Ketersediaan } \\
\text { Teknologi }\end{array}$} & Nila Crispy & 0,42 & 1 & \multirow{3}{*}{0,3} \\
\hline & Instan Jahe & 0,25 & 3 & \\
\hline & Terong Crispy & 0,33 & 2 & \\
\hline \multirow{3}{*}{$\begin{array}{l}\text { Permintaan } \\
\text { Pasar }\end{array}$} & Nila Crispy & 0,33 & 2 & \multirow{3}{*}{2} \\
\hline & Instan Jahe & 0,54 & 1 & \\
\hline & Terong Crispy & 0,13 & 3 & \\
\hline \multirow{3}{*}{$\begin{array}{l}\text { Lingkup } \\
\text { Budaya }\end{array}$} & Nila Crispy & 0,20 & 3 & \multirow{3}{*}{0} \\
\hline & Instan Jahe & 0,57 & 1 & \\
\hline & Terong Crispy & 0,23 & 2 & \\
\hline
\end{tabular}

Sumber : Data primer diolah (2015)

Berdasarkan Tabel 2, bahwa produk yang memperoleh prioritas pertama berdasarkan kriteria ketersediaan SDM yakni produk Instan Jahe dengan bobot sebesar 0,44 . Pada dasarnya, dari ketiga produk yang dihasilkan industri rumah tangga Raflesia tersebut, produk Instan Jahe merupakan produk yang modalnya paling besar dan membutuhkan waktu produksi yang cukup lama. Kerumitan dalam proses produksi, menjadikan produk Instan Jahe benar-benar harus memperhatikan sumber daya manusia yang ada agar nantinya tidak menimbulkan kerugian.

Berdasarkan kriteria ketersediaan teknologi produk yang memperoleh urutan prioritas pertama yakni produk Nila Crispy dengan bobot sebesar 0,42. Tersedianya teknologi yang memadai dan modern dapat menunjang dan memberikan kemudahan dalam proses produksi industri rumah tangga Raflesia. Untuk itulah, dalam mengolah produk olahan ikan nila dibutuhkan penggunaan teknologi yang modern dan tepat guna agar dapat menjaga dan meningkatkan kualitas produk baik rasa maupun kandungannya. Sedangkan pada penilaian alternatif produk yang memperoleh prioritas utama berdasarkan kriteria permintaan pasar merupakan produk Instan Jahe dengan bobot 0,54.

152 | Dwi Lestari, Ketut Sukiyono, dan Redy Badrudin, Strategi Pengembangan. 
Produk Instan Jahe masih diminati konsumen, terbukti sampai sejauh ini produk Instan Jahe yang awal mulanya diusahakan pada tahun 2004 masih mampu bertahan hingga saat ini.

Dari Tabel 2, penilaian bobot alternatif produk berdasarkan kriteria lingkup budaya yang memperoleh prioritas utama merupakan produk Instan Jahe dengan bobot 0,57 . Selain produk Instan Jahe ramah lingkungan dan tidak merusak budaya setempat, produk Instan Jahe juga masih sangat diminati konsumen. Selain itu, secara turun temurun masyarakat sudah mengenal dan mengetahui tentang khasiat dari jahe itu sendiri, budaya dan nilai-nilai masyarakat lebih melekat pada produk Instan Jahe.

Tabel 3. Analisis Alternatif Produk Unggulan

\begin{tabular}{lccc}
\hline \multicolumn{1}{c}{ Alternatif Produk } & Bobot & Prioritas & Rasio Inkonsistensi (\%) \\
\hline Nila Crispy & 0,35 & 2 & 1 \\
Instan Jahe & 0,43 & 1 & \\
Terong Crispy & 0,22 & 3 & \\
\hline Sumber : Data primer diolah (2015) & &
\end{tabular}

Apabila dilihat pada Tabel 3 di atas, alternatif produk yang memperoleh prioritas pertama merupakan produk Instan Jahe dengan nilai bobot sebesar 0,43. Dalam hal ini, produk Instan Jahe mendapat prioritas utama untuk dikembangkan sebagai produk unggulan industri rumah tangga Raflesia. Produk Instan Jahe memiliki prospek yang cukup bagus untuk lebih dikembangkan dan ditingkatkan kualitasnya. Selain banyak diminati konsumen, produk Instan Jahe juga memberikan omset yang paling besar dibandingkan dengan produk lain yang diproduksi industri rumah tangga Raflesia. Produk Instan Jahe merupakan produk asli daerah yang memanfaatkan potensi daerah yang bersangkutan, produk yang sangat lekat dengan pengetahuan tradisional dan kearifan local.

\section{Analisis Pemilihan Strategi Pengembangan Pemasaran Produk Instan Jahe}

Sama seperti penentuan produk unggulan, penentuan strategi pemasaran juga diawali dengan penentuan bobot pada masing - masing kriteria penentuan strategi pemasaran. Hasil analisa disajikan pada Tabel 4.

Tabel 4. Nilai Bobot Kriteria Pemilihan Strategi Pengembangan Pemasaran

\begin{tabular}{lcc}
\hline \multicolumn{1}{c}{ Kriteria } & Bobot & Prioritas \\
\hline Modal & 0,29 & 2 \\
Keunikan Produk & 0,35 & 1 \\
Legalitas Produk & 0,19 & 3 \\
Teknologi & 0,17 & 4 \\
\hline Rasio Inkonsistensi Keseluruhan (\%) & & 0,1
\end{tabular}

Sumber : Data primer diolah (2015) 
Berdasarkan pengolahan tersebut, diketahui bahwa kriteria keunikan produk menjadi prioritas utama dalam pemilihan strategi pengembangan pemasaran produk Instan Jahe dengan besar bobot tertinggi yakni 0,35. Kriteria keunikan produk menjadi prioritas utama karena banyak yang berpendapat bahwa dengan aspek keunikan produk, semakin unik, semakin khas dan semakin berbeda produk Instan Jahe yang dihasilkan industri rumah tangga Raflesia dengan produk Instan Jahe lainnya yang beredar di pasaran, maka produk Instan Jahe dapat dengan mudah memasuki pasar sasaran dan tetap eksis di pasaran sehingga dapat mempermudah dalam menerapkan strategi pemasaran yang tepat. Kriteria teknologi menjadi prioritas terakhir dalam pemilihan strategi pengembangan pemasaran produk Instan Jahe dengan besar bobot 0,17 . Teknologi yang dimaksud merupakan media pemasaran yang digunakan industri rumah tangga Raflesia dalam memasarkan produk Instan Jahe. Teknologi atau media pemasaran dapat memberikan kemudahankemudahan dalam menyampaikan maupun menyalurkan dan mendistribusikan produk agar sampai ke konsumen.

Tabel 5. Nilai Bobot Alternatif Strategi Pengembangan Pemasaran Produk Instan Jahe

\begin{tabular}{|c|c|c|c|c|}
\hline Kriteria & Alternatif Strategi & Bobot & Prioritas & $\begin{array}{c}\text { Rasio } \\
\text { Inkonsistensi } \\
(\%)\end{array}$ \\
\hline \multirow{4}{*}{ Modal } & Strategi Produk & 0,24 & 3 & \multirow{4}{*}{2} \\
\hline & Strategi Promosi & 0,33 & 1 & \\
\hline & Strategi Harga & 0,17 & 4 & \\
\hline & Strategi Distribusi & 0,26 & 2 & \\
\hline \multirow{4}{*}{$\begin{array}{c}\text { Keunikan } \\
\text { Produk }\end{array}$} & Strategi Produk & 0,34 & 1 & \multirow{4}{*}{1} \\
\hline & Strategi Promosi & 0,30 & 2 & \\
\hline & Strategi Harga & 0,15 & 4 & \\
\hline & Strategi Distribusi & 0,21 & 3 & \\
\hline \multirow{4}{*}{$\begin{array}{c}\text { Legalitas } \\
\text { Produk }\end{array}$} & Strategi Produk & 0,33 & 1 & \multirow{4}{*}{0} \\
\hline & Strategi Promosi & 0,28 & 2 & \\
\hline & Strategi Harga & 0,20 & 3 & \\
\hline & Strategi Distribusi & 0,19 & 4 & \\
\hline \multirow{4}{*}{ Teknologi } & Strategi Produk & 0,17 & 3 & \multirow{4}{*}{2} \\
\hline & Strategi Promosi & 0,39 & 1 & \\
\hline & Strategi Harga & 0,16 & 4 & \\
\hline & Strategi Distribusi & 0,28 & 2 & \\
\hline
\end{tabular}

Sumber : Data primer diolah (2015)

Strategi promosi menjadi prioritas utama dalam pemilihan strategi pengembangan pemasaran produk Instan Jahe dengan bobot sebesar 0,33. Industri rumah tangga Raflesia belum banyak dikenal secara umum oleh

154 | Dwi Lestari, Ketut Sukiyono, dan Redy Badrudin, Strategi Pengembangan. 
masyarakat luas sehingga perlu dilakukannya strategi promosi. Strategi harga pada kriteria modal menjadi prioritas keempat dalam pemilihan strategi pengembangan pemasaran produk Instan Jahe industri rumah tangga Raflesia dengan besar bobot 0,17. Dalam hal ini, industri rumah tangga Raflesia tidak mengalami kesulitan dalam menentukan harga, karena disesuaikan dengan biaya produksi yang dikeluarkan.

Berdasarkan kriteria keunikan produk, strategi produk menjadi prioritas utama dalam pemilihan strategi pengembangan pemasaran produk Instan Jahe industri rumah tangga Raflesia dengan besar bobot 0,34. Untuk menciptakan produk yang unik, industri rumah tangga Raflesia lebih harus menciptakan inovasi-inovasi baru untuk pengembangan produk Instan jahe sehingga menjadikan produk Instan Jahe Raflesia berbeda dengan produk Instan Jahe yang sudah ada di pasaran. Strategi harga dalam pemilihan strategi pengembangan pemasaran produk Instan Jahe menjadi prioritas keempat dengan bobot sebesar 0,15. Penetapan harga yang sesuai dan dapat dijangkau konsumen dapat menarik konsumen untuk membeli produk Instan Jahe yang sudah ditawarkan.

Berdasarkan kriteria legalitas produk, strategi produk menjadi prioritas pertama dalam pemilihan strategi pengembangan pemasaran produk Instan Jahe industri rumah tangga Raflesia dengan bobot sebesar 0,33. Agar produk Instan Jahe yang diproduksi industri rumah tangga Raflesia dapat dipasarkan secara luas dan legal, maka produk Instan Jahe harus meningkatkan mutu dan kualitasnya. Strategi distribusi menjadi prioritas keempat dalam pemilihan strategi pengembangan pemasaran produk Instan Jahe industri rumah tangga dengan besar bobot 0,19 . Pendistribusian produk yang dilakukan secara tepat dapat membantu konsumen untuk mendapatkan produk yang diinginkan dengan mudah. Penempatan produk di tempat yang strategis dan mudah dijangkau dapat memberi peluang untuk menciptakan konsumen yang loyal akan produk tersebut.

Berdasarkan kriteria teknologi, strategi promosi menjadi prioritas pertama dengan besar bobot 0,39 . Teknologi dalam pemasaran merupakan sumber daya pendukung yang berperan penting dalam meningkatkan eksistensi industri rumah tangga Raflesia. Menurut Fatma A.F (2014), fasilitas-fasilitas penunjang dalam pelaksanaan kegiatan promosi cukup berpengaruh terhadap pemilihan kegiatan promosi dalam memperlancar kegiatan promosi. Strategi harga menjadi prioritas keempat dalam pemilihan strategi pengembangan produk Instan Jahe industri rumah tangga Raflesia dengan besar bobot 0,16. Dengan memanfaatkan teknologi sebagai media pemasaran yang tepat, harga dapat ditetapkan sesuai dengan biaya operasional yang sudah dikeluarkan sehingga tidak menimbulkan kerugian bagi industri rumah tangga Raflesia. 
Tabel 6. Analisis Alternatif Strategi Pengembangan Pemasaran Produk Instan Jahe

\begin{tabular}{lccc}
\hline Alternatif Strategi & Bobot & Prioritas & Rasio Inkonsistensi (\%) \\
\hline Strategi Produk & 0,28 & 2 & \\
Strategi Promosi & 0,32 & 1 & 1 \\
Strategi Harga & 0,17 & 4 & \\
Strategi Distribusi & 0,23 & 3 & \\
\hline
\end{tabular}

Sumber : Data primer diolah (2015)

Berdasarkan Tabel 6 di atas, diketahui bahwa strategi promosi menjadi prioritas pertama dalam pengembangan pemasaran produk Instan Jahe industri rumah tangga Raflesia dengan bobot sebesar 0,32. Hal ini didasarkan pada keadaan industri rumah tangga Raflesia yang secara umum belum banyak yang mengetahui tentang profil industri maupun produk yang dihasilkan. Banyak yang belum mengetahui apa manfaat yang diperoleh dari mengkonsumsi produknya maupun keunikan dan cita rasa produk yang dihasilkan industri rumah tangga Raflesia yang dalam hal ini merupakan produk Instan Jahe. Hal ini sesuai dengan penelitian yang pernah diakukan oleh Wahyuningsih (2014) bahwa promosi menjadi prioritas utama dalam analisis faktor bauran pemasaran minuman kopi pada Coffe Story Malang. Menurut Simorangkir (2009) dalam Wahyuningsih (2014), betapapun berkualitasnya suatu produk bila pelanggan belum pernah mendengarnya dan tidak yakin bahwa produk tersebut akan berguna bagi mereka, maka mereka tidak akan pernah membelinya

Menurut Kotler dan Armstrong (2008), tahap-tahap yang biasa dilalui konsumen dalam proses mereka untuk melakukan pembelian meliputi kesadaran, pengetahuan, rasa suka, preferensi, keyakinan dan pembelian. Agar dapat mempengaruhi dan meyakinkan konsumen untuk menjadi pelanggan setia, maka kegiatan promosi sebaiknya dilakukan secara kontinyu agar dapat menumbuhkan persepsi konsumen terhadap pencitraan merk produk dan meyakinkan konsumen terhadap kelebihan-kelebihan produk Instan Jahe Raflesia.

Prioritas yang terakhir diperoleh oleh strategi harga dalam pemilihan strategi pengembangan pemasaran produk Instan Jahe industri rumah tangga Raflesia dengan bobot 0,17. Strategi harga mendapat urutan prioritas keempat dikarenakan penetapan harga yang sesuai dengan daya beli masyarakat tentu akan mendukung keputusan pembelian konsumen.

156 | Dwi Lestari, Ketut Sukiyono, dan Redy Badrudin, Strategi Pengembangan. 


\section{SIMPULAN DAN SARAN}

\section{SIMPULAN}

1. Alternatif produk unggulan industri rumah tangga Raflesia yang menjadi prioritas pertama merupakan produk Instan Jahe. Kemudian prioritas kedua terdapat pada produk Nila Crispy dan prioritas terakhir terdapat pada produk Terong Crispy.

2. Strategi pengembangan pemasaran untuk produk Instan Jahe industri rumah tangga Raflesia yang menjadi prioritas pertama terdapat pada strategi promosi, diikuti prioritas kedua terdapat pada strategi produk. Prioritas ketiga terdapat pada strategi distribusi dan prioritas keempat terdapat pada strategi harga.

\section{SARAN}

1. Perlu dilakukannya pengembangan produk dan pembinaan khusus terhadap produk yang potensial untuk dikembangkan terutama produk Instan Jahe yang menjadi produk unggulan industri rumah tangga Raflesia misalnya dengan menjaga kontinuitas produksi dengan selalu mengupayakan ketersediaan bahan baku yang memenuhi kualitas dan tepat waktu serta mengikuti perkembangan pasar agar produk Instan Jahe tetap dapat mengikuti keinginan konsumen dan tetap dapat eksis di pasaran.

2. Perlu dilakukannya peningkatan strategi promosi secara kontinyu untuk meningkatkan eksistensi produk instan jahe Raflesia misalnya dengan aktif ikut di acara pameran maupun event-event penting baik tingkat daerah maupun tingkat nasional. Kemudian mensosialisasikan produk minuman instan jahe sebagai produk minuman kesehatan dengan menjelaskan manfaat yang diperoleh dari produk minuman instan jahe tersebut.

\section{DAFTAR PUSTAKA}

BPS Provinsi Bengkulu. 2013. Statistik Daerah Kabupaten Bengkulu Utara. Bengkulu.

. 2014. Provinsi Bengkulu Dalam Angka. Bengkulu.

Fatma, Aulia Fitria. 2014. Analisis Strategi Promosi Menggunakan Metode Analytical Hierarchy Process (AHP) (Studi Kasus di PT. Sinar Sosro Kantor Penjualan Wilayah (KPW) Waru, Sidoarjo-Jawa Timur). Jurnal Lulusan TIP FTP UB Agustus 2014 : 1-8.

Kotler dan Armstrong. 2008. Prinsip-Prinsip Pemasaran : Jilid 2 Edisi Kedua belas. Erlangga : Jakarta.

Soetarto, Agus Muqorobin dan Mabruroh. 2011. Produk Unggulan dan Nilai PAD : Kasus di Kabupaten Sukoharjo, Jawa Tengah. Seminar Nasional 
Ilmu Ekonomi Terapan 2011. Universitas Muhammadiyah Surakarta. Solo.

Wahyuningsih, Ninik. 2014. Analisis Bauran Pemasaran Minuman Kopi Menggunakan Metode Analytical Hierarchy Process (AHP) dan Technique for Order Preference by Similarity to Ideal Solution (TOPSIS) (Studi Kasus pada Coffe Story Malang). Jurnal Lulusan TIP FTP UB September 2014 : 1-10.

158 | Dwi Lestari, Ketut Sukiyono, dan Redy Badrudin, Strategi Pengembangan. 